\title{
Catalytic Performances of Platinum Containing PLLA Macrocomplex in the Hydrogenation of $\alpha, \beta$-Unsaturated Carbonyl Compounds
}

\author{
Mattia Bartoli ${ }^{1}$, Luca Rosi ${ }^{1, *}$, Benedetta Mini ${ }^{1}$, Giorgio Petrucci ${ }^{1}$, Elisa Passaglia ${ }^{2}$ (D) \\ and Marco Frediani ${ }^{1, *(D)}$ \\ 1 Department of Chemistry "Ugo Schiff”, University of Florence, Via della Lastruccia 3-13, \\ 50019 Sesto Fiorentino, Italy \\ 2 Italian National Council for Research - Institute for the Chemistry of OrganoMetallic Compounds, \\ Secondary Station of Pisa (CNR-ICCOM SS Pisa), Via Moruzzi 1, 56124 Pisa, Italy \\ * Correspondence: luca.rosi@unifi.it (L.R.); marco.frediani@unifi.it (M.F.); \\ Tel.: +39-0554-573-458 (L.R.); +39-0554-573-459 (M.F.)
}

Received: 27 June 2019; Accepted: 7 August 2019; Published: 8 August 2019

\begin{abstract}
The synthesis of a bipyridine poly(lactic acid) carboxylic end-capped macroligand coordinated to a platinum center was reported. The reaction between the metal ion and the polymeric ligand was run in a very efficient way through a one-step synthesis and the complex was tested for selective hydrogenation of $\alpha, \beta$-carbonyl compounds. High selectivity was proven for double bond hydrogenation of 2-cyclohexen-1-one (up to 99\%) and the production of 1-butanol from (E)-but-2-enal. Moreover, the catalytic system was still active after three catalytic cycles.
\end{abstract}

Keywords: poly(lactic acid); hydrogenation; polymer functionalization; macroligands

\section{Introduction}

The development of new catalysts is one of the breakthroughs of applied chemistry [1]. In the field of catalysis, hydrogenation plays a relevant role because this kind of process is largely used in the oil [2-4] and pharmaceutical [5,6] industries for refining or synthetic purposes. Furthermore, great interest has also been devoted to enantio [7] and chemo [8] selective conversions. Among all substrates, the multifunctional ones are quite challenging due to the possibility of the simultaneous transformation of one or all of the functionalities present. This normally induces a severe decrement of the hydrogenation selectivity and an interesting case study is represented by the $\alpha, \beta$-unsaturated carbonyl compounds [9]. Over the years, several systems have been developed for the selective hydrogenation of these substrates based on a plethora of metal frameworks (i.e., $\mathrm{Cu}$ [10], $\mathrm{Au}$ [11], Ni [12], Rh [13], Ru [14], Pd [15], and Pt [16,17]) with the aim to obtain a selective reduction of carbon-carbon or carbon-oxygen double bond or both. Among all available catalysts, noble metal based nanoparticles have astonishing properties of selectivity but still require a complex multi-step synthesis [18-21]. Recently, Bartoli et al. [22] proposed a new approach focused on the use of palladium bonded to a poly(lactic acid) macroligand. The catalytic system showed the same time advantages of a homogenous catalyst and the easy recyclability of a heterogeneous one. The use of Pd containing poly(lactic acid) systems is a well-established practice for selective hydrogenation of carbon-carbon double bonds [23-25], achieving great results for its selectivity and reusability.

In this paper, the use of a carboxylic end-capped poly(lactic acid) called macroligand was employed for the synthesis of platinum-based recyclable catalysts. The catalytic system was tested for selective hydrogenation of $\alpha, \beta$-unsaturated carbonyl compounds under several conditions to extend the use of macrocyclic ligands to the synthesis of other transition metal-containing catalysts. 


\section{Materials and Methods}

\subsection{Materials and Instrumentations}

2-Cyclohexen-1-one, (E)-but-2-enal, dry $\mathrm{CH}_{2} \mathrm{Cl}_{2}(\geq 99 \%)$, n-hexane ( $\left.\geq 98 \%\right)$, acetonitrile $(\geq 99 \%)$, chloroform $(\geq 99 \%)$, deuterochloroform $\left(\mathrm{CDCl}_{3}, 100 \%, 99.9 \mathrm{D}\right)$ toluene $(\geq 99 \%)$, hexadeuterodimethylsulfoxide (DMSO- $d_{6}, 100 \%, 99.9$ D), THF (HPLC grade, $\geq 99.8 \%$ ), and $\mathrm{PtCl}_{2}$ were purchased from Aldrich. L-lactide was purchased from Purac. 4-Methyl-4'-(hydroxymethyl)-2,2'-bipyridine (Bipy) was purchased from Imperial Chemical Industries(I.C.I. $)(\geq 99.8 \%)$.

GC analyses were carried out on a Shimadzu 2010 (VFWAX column $30 \mathrm{~m} \times 0.25 \mathrm{~mm} \times 0.25 \mu \mathrm{m}$ )

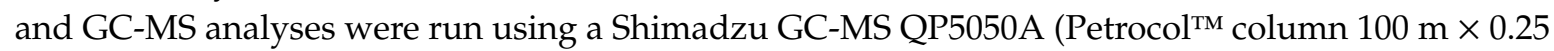
$\mathrm{mm} \times 0.5 \mu \mathrm{m})$.

NMR analyses were performed with a Varian model GEMINI $400 \mathrm{MHz}$ using $\mathrm{CDCl}_{3}$ or DMSO- $d_{6}$ as the solvent. Integral errors were $\pm 5 \%$.

GPC analyses were carried out with a Waters model binary HPLC 1525 system equipped with three columns (Shodex KF-802.5, KF-803, KF-804) and a refractive index detector Wyatt T-REX Optilab. Analyses were performed with THF as the eluant.

UV-Vis analysis was carried out using a Varian model Cary 4000 UV-Vis spectrophotometer.

Fourier transform infrared spectroscopy (FTIR) was performed using a Shimadzu model IR Affinity-1, equipped with a Golden Gate single reflection diamond ATR accessory supplied by Specac.

Elemental analysis was carried out using a Perkin-Elmer $240 \mathrm{CHN}$ model.

Differential calorimetric analyses were carried out using a Perkin Elmer Pyris-1-dsc. Samples were tested from $40{ }^{\circ} \mathrm{C}$ to $180^{\circ} \mathrm{C}$ with a heating rate of $10{ }^{\circ} \mathrm{C} / \mathrm{min}$.

Catalytic reactions: Homogeneous catalytic hydrogenations of $\alpha, \beta$-unsaturated substrates were carried out in a $150 \mathrm{~mL}$ stainless steel homemade autoclave thermostated in an oil bath $\left( \pm 1{ }^{\circ} \mathrm{C}\right)$ containing a glass vessel. The substrate, solvent, and catalyst were introduced in the glass vessel, under a nitrogen atmosphere, then the autoclave was closed. The autoclave was pressurized at room temperature with hydrogen, then stirred and heated at the prefixed temperature for the established time. At the end of the reaction, the autoclave was rapidly cooled to room temperature, the gas vented, and the solution collected and transferred into a $50 \mathrm{~mL}$ Schlenk tube. A sample of the solution was taken for the GC and GC-MS analyses. Each test was repeated three times, and the mean value was reported.

\subsection{Synthesis of Macroligand, Macrocomplex, and Reference Catalyst}

\subsubsection{Synthesis of Macroligand PLLA-Bipy}

In a Schlenk tube, L-lactide $(4.00 \mathrm{~g}, 28.0 \mathrm{mmol})$ was heated at $135^{\circ} \mathrm{C}$ under a nitrogen atmosphere in the presence of $\mathrm{Sn}(\mathrm{Oct})_{2}(56.3 \mathrm{mg}, 0.139 \mathrm{mmol})$ and Bipy $(0.400 \mathrm{mmol})$ for $3 \mathrm{~h}$. Afterward, the reaction mixture was allowed to cool to room temperature and residual crystalline L-lactide, which sublimated during the reaction, was removed mechanically from the Schlenk tube. The crude reaction product was then dissolved in $\mathrm{CH}_{2} \mathrm{Cl}_{2}(20 \mathrm{~mL})$ and precipitated upon the addition of n-hexane $(30.0 \mathrm{~mL})$, giving an off-white solid powder, which was separated from the solution by filtration, washed several times with n-hexane, and dried in vacuum at room temperature for $12 \mathrm{~h}$.

${ }^{1} \mathrm{H}-\mathrm{NMR}\left(\mathrm{CDCl}_{3}, 400 \mathrm{MHz}, \mathrm{ppm}\right): \delta=8.67\left(\mathrm{~d}, 1 \mathrm{H}, J=1.7 \mathrm{~Hz}, \mathrm{H}^{\prime}\right), 8.53(\mathrm{~d}, 1 \mathrm{H}, J=1.7 \mathrm{~Hz}, \mathrm{H} 6)$, $8.52\left(\mathrm{~s}, 1 \mathrm{H}, \mathrm{H}\right.$ 3), $8.23\left(\mathrm{~s}, 1 \mathrm{H}, \mathrm{H} 3^{\prime}\right), 7.21$ (d, 1H, J = 2.1 Hz, H 5'), 7.19 (d, 1H, J = 2.6 Hz, H 5), 5.29 (s, 2H, $\mathrm{CH}_{2}$ on $\mathrm{C} 4$ of Bipy), 5.24-4.96 (bs, $135 \mathrm{CH}$, in chain), 4.37 (q, $1 \mathrm{H}, J=2.3 \mathrm{~Hz}, \mathrm{CH}$ end chain), 2.47 (s, 3H, $\mathrm{CH}_{3}$ of Bipy), 1.86-1.05 (bs, 406, $\mathrm{CH}_{3}$ PLA).

FT-IR $\left(\mathrm{cm}^{-1}\right)$ : 3007-2953 (w, vCH), $1748(\mathrm{~s}, v \mathrm{CO}), 1452(\mathrm{~m}, \operatorname{vasHCH}), 1382(\mathrm{~m}, v \mathrm{CH}), 1359(\mathrm{~m}$, vHCH), 1180 (s, vasCOC), 1128-1043 (s, vCO), 995 (w, vCCH $\left.\mathrm{CH}_{3}\right), 871$ (m, vOCC).

Molecular weight (g/mol): 11,590 , Polydispersity index: 1.9 , Yields (wt.\%): $93, \mathrm{Tg}: 55^{\circ} \mathrm{C}, \mathrm{Tf}: 161^{\circ} \mathrm{C}$. 


\subsubsection{Synthesis of the Macrocomplex Pt(PLLA-Bipy) $\mathrm{Cl}_{2}$}

In a single neck round bottom flask, PLLA-Bipy $(2.00 \mathrm{~g}, 0.14 \mathrm{mmol})$ and $\mathrm{PtCl}_{2}(45 \mathrm{mg}, 0.17 \mathrm{mmol})$ were dissolved in acetonitrile $(20 \mathrm{~mL})$ and refluxed for $16 \mathrm{~h}$. Afterward, the reaction mixture was cooled to room temperature and the crude reaction product was recovered through filtration and washed three times with n-hexane. The yellow powder was dried in vacuum at room temperature for $12 \mathrm{~h}$.

${ }^{1} \mathrm{H}-\mathrm{NMR}\left(\mathrm{CDCl}_{3}, 400 \mathrm{MHz}, \mathrm{ppm}\right): \delta=9.70\left(\mathrm{~d}, 1 \mathrm{H}, J=1.7 \mathrm{~Hz}, \mathrm{H} 6^{\prime}\right), 9.54(\mathrm{~d}, 1 \mathrm{H}, J=1.7 \mathrm{~Hz}, \mathrm{H} 6)$, $7.95\left(\mathrm{~s}, 1 \mathrm{H}, \mathrm{H}\right.$ 3), $7.91\left(\mathrm{~s}, 1 \mathrm{H}, \mathrm{H} 3^{\prime}\right), 7.42\left(\mathrm{~d}, 1 \mathrm{H}, J=2.1 \mathrm{~Hz}, \mathrm{H} 5^{\prime}\right), 7.37(\mathrm{~d}, 1 \mathrm{H}, J=2.6 \mathrm{~Hz}, \mathrm{H} 5), 5.29(\mathrm{~s}, 2 \mathrm{H}$, $\mathrm{CH}_{2}$ on $\mathrm{C} 4$ of Bipy), 5.26-5.05 (bs, $133 \mathrm{CH}, \mathrm{CH}$ in chain), 4.37 (q, $1 \mathrm{H}, \mathrm{J}=2.3 \mathrm{~Hz}, \mathrm{CH}$ end chain), 2.47 (s, $3 \mathrm{H}, \mathrm{CH}_{3}$ of Bipy), $1.86-1.05$ (bs, $400 \mathrm{CH}_{3}$ end chain of PLA).

FT-IR $\left(\mathrm{cm}^{-1}\right)$ : 3012-2956 (w, vCH), 1749 (s, vCO), $1456(\mathrm{~m}$, vasHCH), $1384(\mathrm{~m}, \sigma \mathrm{CH} 3), 1359$ (m, vHCH), 1182 (s, vasCOC), 1130-1041 (s, vCO), $966\left(\mathrm{w}, v \mathrm{CCH}_{3}\right), 871(\mathrm{~m}, \mathrm{vOCC})$.

Yields (wt.\%): $57 \mathrm{Tg}: 59^{\circ} \mathrm{C}$ Tf: $166^{\circ} \mathrm{C}$.

\subsubsection{Synthesis of the Complex $\mathrm{Pt}(\mathrm{Bipy}) \mathrm{Cl}_{2}$}

In a single neck round bottom flask, Bipy $(80.0 \mathrm{mg}, 0.4 \mathrm{mmol})$ and $\mathrm{PtCl}_{2}(104 \mathrm{mg}, 0.4 \mathrm{mmol})$ were dissolved in acetonitrile $(20 \mathrm{~mL})$ and refluxed for $16 \mathrm{~h}$. Afterward, the reaction mixture was cooled to room temperature and the crude reaction product was recovered through filtration and washed three times with n-hexane. The yellow powder was dried in vacuum at room temperature for $12 \mathrm{~h}$.

${ }^{1} \mathrm{H}-\mathrm{NMR}$ (DMSO, $\left.400 \mathrm{MHz}, \mathrm{ppm}\right): \delta=9.16\left(\mathrm{~d}, 1 \mathrm{H}, \mathrm{Hb}^{\prime}, J=1.5 \mathrm{~Hz}\right), 8.92(\mathrm{~d}, 1 \mathrm{H}, \mathrm{H} 6, J=1.2 \mathrm{~Hz})$, $8.48\left(\mathrm{~s}, 1 \mathrm{H}, \mathrm{H} 3^{\prime}\right), 8.42(\mathrm{~s}, 1 \mathrm{H}, \mathrm{H} 3), 7.43(\mathrm{~d}, 1 \mathrm{H}, \mathrm{H} 5, J=1.2 \mathrm{~Hz}), 7.19\left(\mathrm{~d}, 1 \mathrm{H}, \mathrm{H}^{\prime}, J=1.5 \mathrm{~Hz}\right), 4.61(\mathrm{~s}, 2 \mathrm{H}$, $\left.\mathrm{CH}_{2}\right), 3.65(\mathrm{OH}), 2.36\left(\mathrm{~s}, 3 \mathrm{H}, \mathrm{CH}_{3}\right)$.

${ }^{13} \mathrm{C}-\mathrm{NMR}$ (DMSO, $75 \mathrm{MHz}, \mathrm{ppm}$ ): $\delta=157.3$ (s, C 4') 153.1 (s, C 2,2' ), 148.4 (s, C 6,6'), 147.8 (s, C 4), 128.5 (s, C 3), 125.1 (s, C 3'), $124.7\left(\mathrm{~s}, \mathrm{C}^{\prime}\right), 121.2(\mathrm{~s}, \mathrm{C} 5), 61.7\left(\mathrm{~s}, \mathrm{CH}_{2}\right), 21.5\left(\mathrm{~s}, \mathrm{CH}_{3}\right)$.

FT-IR $\left(\mathrm{cm}^{-1}\right)$ : 3421 (bs, vOH), $3066(\mathrm{w}, v \mathrm{CH}$ aromatic), 2897 (w, vCH aliphatic), $1616(\mathrm{~s}, v \mathrm{C}=\mathrm{C})$, 1427 (s, ring breathing mode), 1056 (s, vCO).

Elemental analysis found (calc.): C: 29.59\% (30.91\%), H 3.32\% (2.59\%), N 5.95\% (6.01\%).

Yields (wt.\%): 57.6 .

\subsection{Catalytic Experiments}

All the catalytic reactions were run with the formation of products according to the reaction scheme reported in Figure 1.

a)
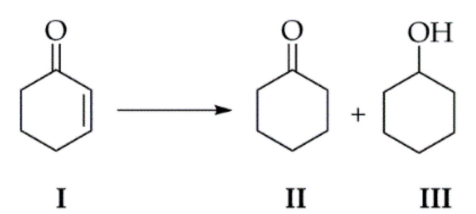

b)

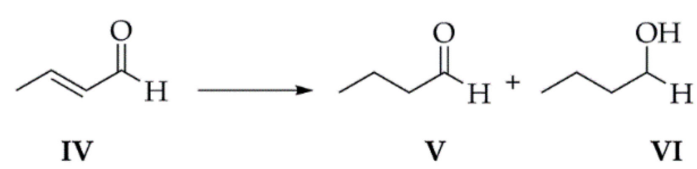

Figure 1. Catalytic reaction pathways of (a) 2-Cyclohexen-1-one, (b) (E)-But-2-enal.

Experiments were carried out using the apparatus reported in the experimental methods using the conditions reported in Table 1. A $10 \mathrm{~mL}$ glass vessel was charged, under a nitrogen atmosphere with I or IV as the substrate $(2.7 \mathrm{mmol})$, the catalyst $(0.0027 \mathrm{mmol}$ catalyst), and toluene $(5 \mathrm{~mL})$. The reactor was then pressurized with hydrogen and heated at $60^{\circ} \mathrm{C}$ for the prefixed time, then cooled at room temperature. The reaction mixture was analyzed as above described. After three catalytic cycles, the catalyst was recovered by filtration and characterized. 
Table 1. Catalytic performances of $\mathrm{Pt}(\mathrm{Bipy}) \mathrm{Cl}_{2}$ (A) and $\mathrm{Pt}(\mathrm{PLLA}-\mathrm{Bipy}) \mathrm{Cl}_{2}$ (B) in the selective hydrogenation of 2-cyclohexen-1-one (I) and (E)-but-2-enal (IV) at $60{ }^{\circ} \mathrm{C}$.

\begin{tabular}{|c|c|c|c|c|c|c|c|c|c|c|c|c|}
\hline Run & Cat & Substrate & $\begin{array}{c}\text { Time } \\
{[\mathrm{h}]}\end{array}$ & $\begin{array}{c}\text { Pressure } \\
{[\mathrm{MPa}]}\end{array}$ & I [\%] & $\begin{array}{c}\text { II } \\
{[\%]}\end{array}$ & $\begin{array}{l}\text { III } \\
{[\%]}\end{array}$ & $\begin{array}{l}\text { IV } \\
{[\%]}\end{array}$ & $\begin{array}{c}\mathrm{V} \\
{[\%]}\end{array}$ & $\begin{array}{c}\text { VI } \\
{[\%]}\end{array}$ & $\begin{array}{c}\text { Conversion }^{\mathrm{a}} \\
{[\%]}\end{array}$ & TOF $^{b}$ \\
\hline ID1 & A & & 3 & 1.1 & 100 & 0 & 0 & - & - & - & - & - \\
\hline ID2 & B & $\mathrm{O}$ & 3 & 1.1 & 27 & 73 & 0 & - & - & - & 73 & 243 \\
\hline ID3 & B & & 6 & 1.1 & 1 & 99 & 0 & - & - & - & 99 & 165 \\
\hline ID4 & $\mathrm{B}^{\mathrm{c}}$ & & 3 & 1.1 & 61 & 39 & 0 & - & - & - & 39 & 130 \\
\hline ID5 & B & & 3 & 2.2 & 5 & 95 & - & - & - & - & 95 & 317 \\
\hline ID6 & $\mathrm{B}^{\mathrm{d}}$ & & 3 & 2.2 & 60 & 40 & - & - & - & - & 40 & 133 \\
\hline ID7 & B & 0 & 3 & 2.2 & - & - & - & 4 & 8 & 88 & 96 & 320 \\
\hline ID8 & B & & 6 & 2.2 & - & - & - & 3 & 8 & 89 & 97 & 161 \\
\hline ID10 & $\mathrm{B}^{\mathrm{e}}$ & $\mathrm{H}$ & 3 & 2.2 & - & - & - & 9 & 4 & 87 & 91 & 303 \\
\hline
\end{tabular}

\section{Results}

\subsection{Platinum Containing Poly(Lactic Acid) Macrocomplex}

Synthesis of bipyridine carboxylic end-capped poly(lactic acid) ligand is an advantageous procedure for the production of several molecular architectures [26]. In this work, the synthesis of $\mathrm{Pt}(\mathrm{PLLA}-\mathrm{Bipy}) \mathrm{Cl}_{2}$ was reported, according to the scheme reported in Figure 2.

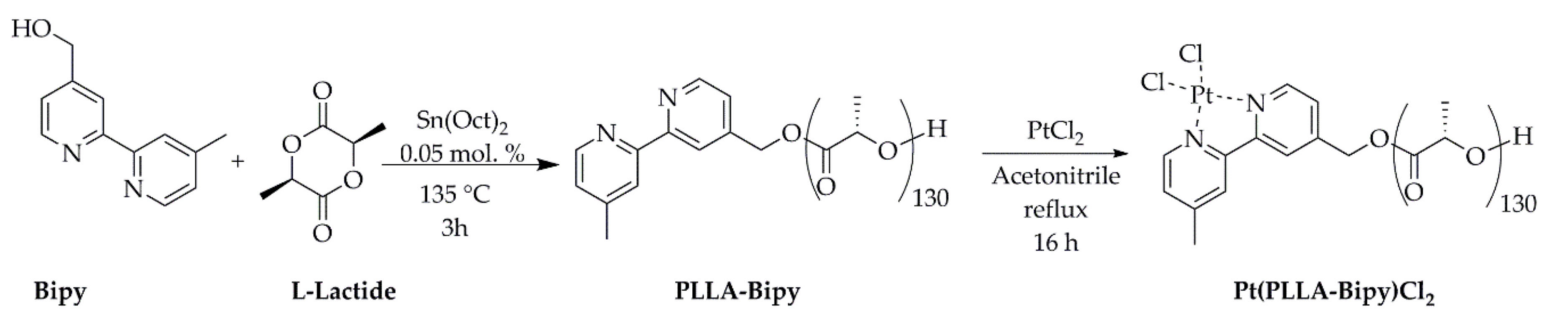

Figure 2. Pathway for the synthesis of $\mathrm{Pt}(\mathrm{PLLA}-\mathrm{Bipy}) \mathrm{Cl}_{2}$ macrocomplex.

Synthesis of the ligand with carboxylic end-capped functionalization was proven by the presence of aromatic signals of Bipy in the region between 8.7-7.4 ppm (Figure 3a).

The formation of the platinum macromplex was detectable by ${ }^{1} \mathrm{H}-\mathrm{NMR}$ spectra, through a comparison of spectra (a) and (b) as reported in Figure 3. The formation of the Pt complex did not affect the number of lactic acid unities in the ligand because the reaction conditions were quite soft. The difference between hydrogen numbers was imputable to several issues: the first and the main relevant among them is the integral processing of the signals that were affected by noise and baseline correction. A\% error in integral evaluations was reported in the experimental. Considering these points, the data for the macromplex and the macroligand are in good agreement among them. For a more precise molecular weight and fragment numbers, the value obtained from GPC analysis must be considered. After the coordination of the platinum ion, signals of aromatic hydrogen shifted to a higher ppm (Figure 3b) when compared with the non-coordinated ligand (Figure 3a). This behavior was in agreement with similar results observed for palladium coordination [26]. This phenomenon is due to the reduction of charge density on the aromatic ring caused by the modification of the $\pi$-orbitals of the Bipy due to the interaction of the electron doublet on the nitrogen atoms with the platinum orbital system as described by several theoretical studies $[27,28]$. Thermal properties of the complex were in good agreement with those previously reported for functionalized poly(lactic acid) [29]. 


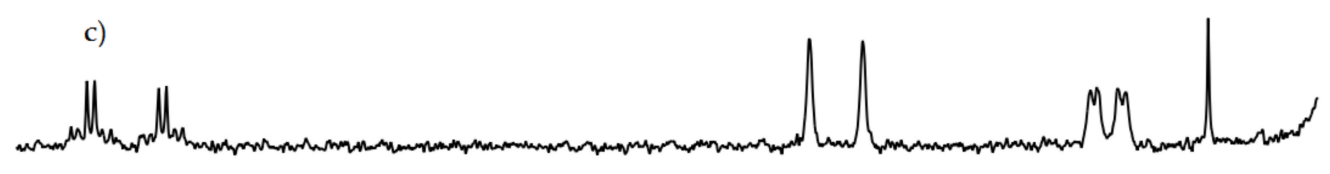

b)

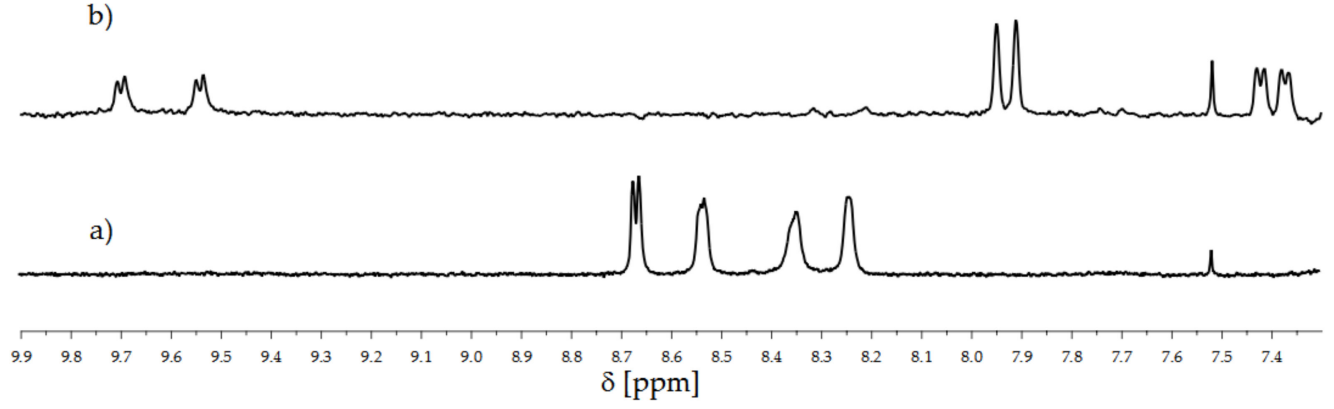

Figure 3. Magnification of the NMR spectra in the aromatic region of (a) PLLA-Bipy, (b) Pt(PLLA-Bipy)Cl ${ }_{2}$ and (c) $\left[\mathrm{Pt}(\mathrm{PLLA}-\mathrm{Bipy}) \mathrm{Cl}_{2}\right]_{2}$ recovered after ID4.

The effect of orbitals interactions was also appreciable in the UV-Vis spectra reported in Figure 4. $\mathrm{Pt}\left(\mathrm{PLLA}-\mathrm{Bipy}_{\mathrm{C}} \mathrm{Cl}_{2}\right.$ (c) and $\mathrm{Pt}(\mathrm{Bipy}) \mathrm{Cl}_{2}$ (a) showed a maximum absorption at $287 \mathrm{~nm}$ and a secondary absorption at 314 and $384 \mathrm{~nm}$ while PLLA-Bipy (b) showed only the absorption at $287 \mathrm{~nm}$. Additional absorption bands were an evident proof of the coordination of Pt to Bipy moieties, in agreement with the NMR spectra above reported.

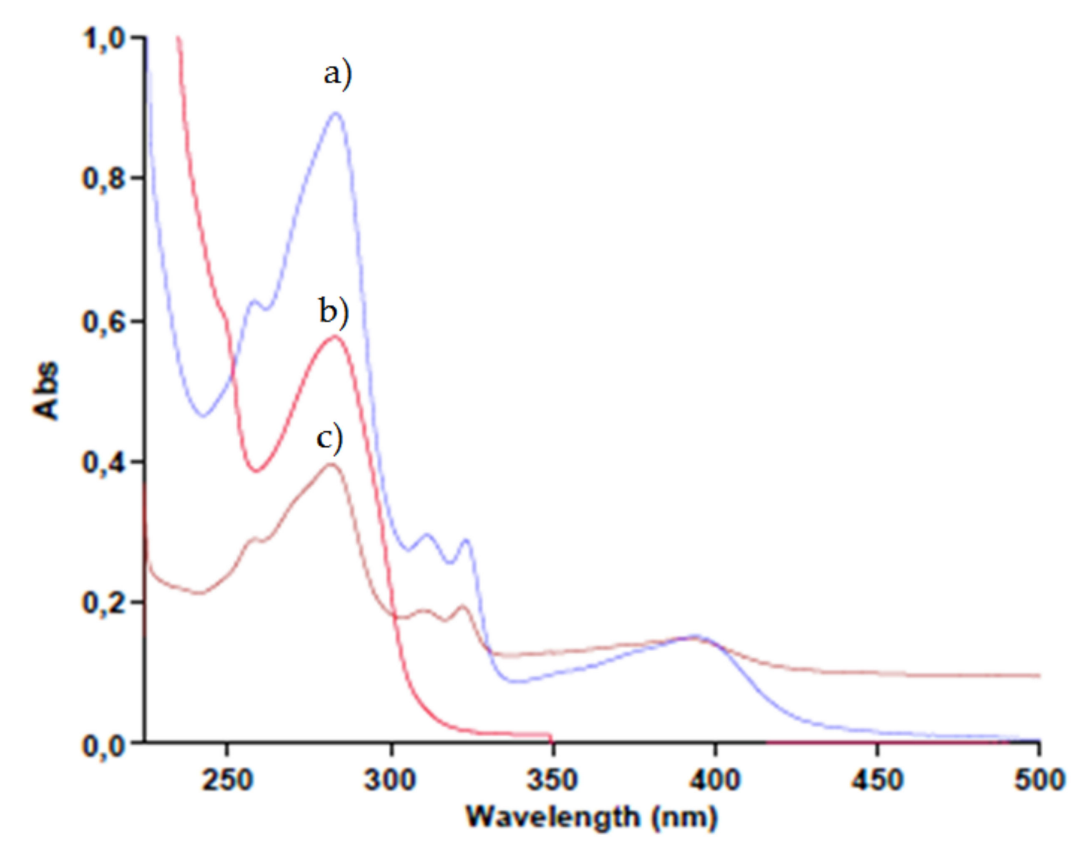

Figure 4. UV-Vis spectra of (a) $\mathrm{Pt}\left(\mathrm{Bipy}_{\mathrm{C}} \mathrm{Cl}_{2}\right.$, (b) PLLA-Bipy and (c) $\mathrm{Pt}(\mathrm{PLLA}-\mathrm{Bipy}) \mathrm{Cl}_{2}$ collected in $\mathrm{CH}_{2} \mathrm{Cl}_{2}$ solution $(\mathrm{M}=0.005 \mathrm{~mol} / \mathrm{L})$.

\subsection{Catalytic Experiments}

The most important advantage for the use of $\mathrm{Pt}(\mathrm{PLLA}-\mathrm{Bipy}) \mathrm{Cl}_{2}$ is the lack of solubility in the reaction medium at room temperature, while it was completely soluble under catalytic conditions (see Figure 5). This behavior, known as the "ponytail" effect, allows catalysis to be carried out in the homogeneous phase while the catalyst may be easily separated at the end of the process as a heterogeneous system. In contrast, the $\mathrm{Pt}(\mathrm{Bipy}) \mathrm{Cl}_{2}$ complex did not show this property. 


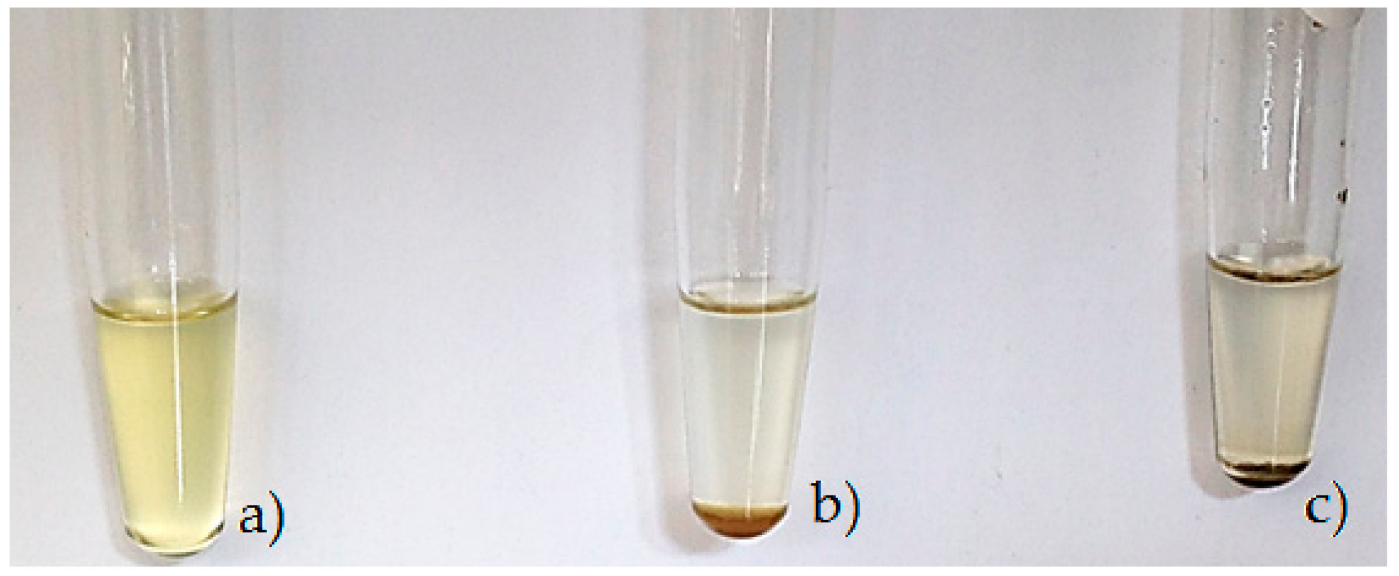

Figure 5. The catalytic reaction mixture of (a) $\mathrm{Pt}(\mathrm{PLLA}-\mathrm{Bipy}) \mathrm{Cl}_{2}$ under reaction conditions, (b) $\mathrm{Pt}(\mathrm{PLLA}-\mathrm{Bipy}) \mathrm{Cl}_{2}$ before and after catalysis at room temperature, (c) $\mathrm{Pt}(\mathrm{Bipy}) \mathrm{Cl}_{2}$ at room and reaction temperature.

Catalytic performances of $\mathrm{Pt}(\mathrm{PLLA}-\mathrm{Bipy}) \mathrm{Cl}_{2}$ and $\mathrm{Pt}(\mathrm{Bipy}) \mathrm{Cl}_{2}$ were tested under different conditions of time and pressure as shown in Table 1.

First, $\mathrm{Pt}(\mathrm{Bipy}) \mathrm{Cl}_{2}$ was tested as a reference catalyst to evaluate its behavior in the hydrogenation of 2-cyclohexen-1-one as a model substrate. The results of ID 1 showed the total inactivity of this catalyst as shown by the absence of hydrogenation products after catalysis. In contrast, the reaction performed in the presence of $\mathrm{Pt}$ (PLLA-Bipy) $\mathrm{Cl}_{2}$ as the catalyst achieved a conversion of $73 \%$ and a total selectivity for the reduction of the carbon-carbon double bond in the same conditions. After increasing the reaction time from 3 to $6 \mathrm{~h}$, the catalytic performances of $\mathrm{Pt}(\mathrm{PLLA}-\mathrm{Bipy}) \mathrm{Cl}_{2}$ reached a conversion of $99 \%$ with a total selectivity toward the reduction of carbon-carbon unsaturation (ID3). The catalyst was still active and selective after three catalytic cycles, although the conversion dropped to $39 \%$. This was probably due to the formation of higher hindered [Pt(PLLA-Bipy) $\left.\mathrm{Cl}_{2}\right]_{2}$ (Figure 6) instead of a merely Pt leaching, according to a theoretical study reported by Kawanishi et al. [30]. This hypothesis was supported by the NMR spectra of the recovered catalysts (Figure 3c), where the resonances of the Bipy ligands slightly shifted and the spectrum did not show any signal of free Bipy. A further increment of hydrogen pressure from 1.1 to 2.2 MPa gave a conversion of $95 \%$ with total selectivity. Under these conditions, the catalyst deactivation after three catalytic runs was the same as ID4. This result supports the deactivation mechanism above-mentioned and exclude the formation of nanoparticles that are more active than molecular complexes [31].<smiles></smiles>

Figure 6. Structure of the hypothesized dimeric specie $\left[\mathrm{Pt}(\mathrm{PLLA}-\mathrm{Bipy}) \mathrm{Cl}_{2}\right]_{2}$. 
The solubility of the catalytic system $\mathrm{Pt}(\mathrm{PLLA}-\mathrm{Bipy}) \mathrm{Cl}_{2}$ is very different from the behavior of other heterogeneous systems previously described $[32,33]$ as it acts as a non-supported catalyst during the reaction, leaving the $\mathrm{C}=\mathrm{O}$ functionality untouched.

Different results were obtained in the hydrogenation of (E)-but-2-enal using the complex $\mathrm{Pt}(\mathrm{PLLA}-\mathrm{Bipy}) \mathrm{Cl}_{2}$ in the same conditions of the previously reported experiments. In these tests, a conversion of $96-97 \%$ was reached using a reaction time of $6 \mathrm{~h}$ and a hydrogen pressure of $2.2 \mathrm{MPa}$ (ID7 and ID8). During the hydrogenation of an $\alpha, \beta$-unsaturated aldehyde, a remarkable selectivity was achieved toward the complete hydrogenation of the $\mathrm{C}=\mathrm{C}$ double bond, but also of the -CHO group with the formation of 1-butanol (selectivity $88-89 \%$ ) and butanal (selectivity $3-4 \%$ ).

The different products formed during the two hydrogenations may be attributed to the high reactivity of the aldehydic group (-CHO) of (E)-but-2-enal if compared with the carbonyl group $(=\mathrm{CO})$ of 2-cyclohexen-1-one.

In the hydrogenation of (E)-but-2-enal the recyclability of the catalyst was very high, and the conversion was reduced by only $5 \%$ after three catalytic cycles.

\section{Conclusions}

In this research, the possibility of realizing the synthesis of bipyridine carboxylic end-capped poly(lactic acid) based macroligand was reported. The macroligand was used for the synthesis of a platinum-containing macrocomplex through a facile one-step coordination procedure The new $\mathrm{Pt}$ macrocomplex showed high activity and selectivity for the hydrogenation of the carbon-carbon double bond of 2-cyclohexen-1-one to the corresponding saturated ketone. In contrast, in the hydrogenation of (E)-but-2-enal, a very promising selectivity toward the formation of 1-butanol (up to 89\%) was achieved.

Furthermore, the catalyst was easily recycled even if it underwent a partial deactivation, especially in the reduction of cyclohexanone, while it remained almost constant after three catalytic runs in the hydrogenation of (E)-but-2-enal.

Author Contributions: Conceptualization: M.B., L.R., and M.F.; Methodology: B.M., M.B., L.R., and G.P.; Formal analysis: B.M., G.P., and E.P.; Resources: L.R. and M.F.; Writing—original draft preparation: M.B.; Writing-review and editing: L.R., M.F., and E.P.; Supervision: M.F.; Funding Acquisition: M.F.

Funding: This research received no external funding

Acknowledgments: We thank MIUR-Italy ("Progetto Dipartimenti di Eccellenza 2018-2022" allocated to the Department of Chemistry "Ugo Schiff”).

Conflicts of Interest: The authors declare no conflicts of interest.

\section{References}

1. Leach, B. Applied Industrial Catalysis; Elsevier: Amsterdam, The Netherlands, 2012.

2. Pevere, E.F.; Vermillion, H.E. Recovery of Viscous Crude Oil. Google Patents. U.S. Patents No. 2,857,002, 21 October 1958.

3. Kodera, Y.; Kato, J.; Ohse, H.; Ohshima, S.; Shimada, K.; Suzuki, M.; Kiriki, Y. Hydrogenation Treatment of Hydrocarbon Oil. Google Patents. U.S. Patents No. 3,716,478, 1973.

4. Scherzer, J.; Gruia, A.J. Hydrocracking Science and Technology; CRC Press: Boca Raton, FL, USA, 1996.

5. Nairoukh, Z.; Wollenburg, M.; Schlepphorst, C.; Bergander, K.; Glorius, F. The formation of all-cis-(multi) fluorinated piperidines by a dearomatization-hydrogenation process. Nat. Chem. 2019, 11, 264. [CrossRef] [PubMed]

6. Campeau, L.-C.; Fogg, D.E. The Roles of Organometallic Chemistry in Pharmaceutical Research and Development; ACS Publications: Washington, DC, USA, 2019.

7. Garbe, M.; Wei, Z.; Tannert, B.; Spannenberg, A.; Jiao, H.; Bachmann, S.; Scalone, M.; Junge, K.; Beller, M. Enantioselective Hydrogenation of Ketones using Different Metal Complexes with a Chiral PNP Pincer Ligand. Adv. Synth. Catal. 2019, 361, 1913-1920. [CrossRef]

8. Lin, L.; Yao, S.; Gao, R.; Liang, X.; Yu, Q.; Deng, Y.; Liu, J.; Peng, M.; Jiang, Z.; Li, S. A highly CO-tolerant atomically dispersed Pt catalyst for chemoselective hydrogenation. Nat. Nanotechnol. 2019, 14, 354. [CrossRef] 
9. Nishimura, S. Handbook of Heterogeneous Catalytic Hydrogenation for Organic Synthesis; Wiley: New York, NY, USA, 2001.

10. Zimmermann, B.M.; Kobosil, S.C.; Teichert, J.F. Catalytic hydrogenation of $\alpha, \beta$-unsaturated carboxylic acid derivatives using copper (i)/N-heterocyclic carbene complexes. Chem. Commun. 2019, 55, 2293-2296. [CrossRef]

11. Milone, C.; Crisafulli, C.; Ingoglia, R.; Schipilliti, L.; Galvagno, S. A comparative study on the selective hydrogenation of $\alpha, \beta$ unsaturated aldehyde and ketone to unsaturated alcohols on Au supported catalysts. Catal. Today 2007, 122, 341-351. [CrossRef]

12. Yang, Y.; Chen, L.; Chen, Y.; Liu, W.; Feng, H.; Wang, B.; Zhang, X.; Wei, M. Selective hydrogenation of furfural on intermetallic compounds with outstanding catalytic performance. Green Chem. 2019. [CrossRef]

13. Azran, J.; Buchman, O.; Amer, I.; Blum, J. Selective hydrogenation of $\alpha, \beta$-unsaturated carbonyl compounds by rhodium trichloride and aliquat ${ }^{\circledR}-336$ in a two-phase liquid system. J. Mol. Catal. 1986, 34, $229-234$. [CrossRef]

14. Ohta, T.; Miyake, T.; Seido, N.; Kumobayashi, H.; Akutagawa, S.; Takaya, H. Asymmetric hydrogenation of unsaturated carbonyl compounds catalyzed by BINAP-Ru (II) complexes. Enantioselective synthesis of $\gamma$-butyrolactones and cyclopentanones. Tetrahedron Lett. 1992, 33, 635-638. [CrossRef]

15. Chen, P.; Li, W.; Wang, Y. Atmospheric hydrogenation of $\alpha, \beta$-unsaturated ketones catalyzed by highly efficient and recyclable Pd nanocatalyst. Catal. Commun. 2019, 125, 10-14. [CrossRef]

16. Ma, H.; Wang, L.; Chen, L.; Dong, C.; Yu, W.; Huang, T.; Qian, Y. Pt nanoparticles deposited over carbon nanotubes for selective hydrogenation of cinnamaldehyde. Catal. Commun. 2007, 8, 452-456. [CrossRef]

17. Musselwhite, N.E.; Wagner, S.B.; Manbeck, K.A.; Carl, L.M.; Gross, K.M.; Marsh, A.L. Activity and selectivity of colloidal platinum nanocatalysts for aqueous phase cyclohexenone hydrogenation. Appl. Catal. A Gen. 2011, 402, 104-109. [CrossRef]

18. Wu, B.; Huang, H.; Yang, J.; Zheng, N.; Fu, G. Selective hydrogenation of $\alpha$, $\beta$-unsaturated aldehydes catalyzed by amine-capped platinum-cobalt nanocrystals. Angew. Chem. Int. Ed. 2012, 51, 3440-3443. [CrossRef] [PubMed]

19. Tsang, S.C.; Cailuo, N.; Oduro, W.; Kong, A.T.; Clifton, L.; Yu, K.K.; Thiebaut, B.; Cookson, J.; Bishop, P. Engineering performed cobalt-doped platinum nanocatalysts for ultraselective hydrogenation. ACS Nano 2008, 2, 2547-2553. [CrossRef] [PubMed]

20. Yuan, Y.; Yao, S.; Wang, M.; Lou, S.; Yan, N. Recent progress in chemoselective hydrogenation of $\alpha$, $\beta$-unsaturated aldehyde to unsaturated alcohol over nanomaterials. Curr. Org. Chem. 2013, 17, 400-413. [CrossRef]

21. Rioux, R.M.; Song, H.; Grass, M.; Habas, S.; Niesz, K.; Hoefelmeyer, J.D.; Yang, P.; Somorjai, G.A. Monodisperse platinum nanoparticles of well-defined shape: Synthesis, characterization, catalytic properties and future prospects. Top. Catal. 2006, 39, 167-174. [CrossRef]

22. Bartoli, M.; Rosi, L.; Petrucci, G.; Armelao, L.; Oberhauser, W.; Frediani, M.; Piccolo, O.; Rathod, V.D.; Paganelli, S. An easily recoverable and recyclable homogeneous polyester-based Pd catalytic system for the hydrogenation of $\alpha, \beta$-unsaturated carbonyl compounds. Catal. Commun. 2015, 69, 228-233. [CrossRef]

23. Frediani, M.; Oberhauser, W.; Rosi, L.; Bartoli, M.; Passaglia, E.; Capozzoli, L. Palladium nanoparticles supported onto stereocomplexed poly (lactic acid)-poly ( $\varepsilon$-caprolactone) copolymers for selective partial hydrogenation of phenylacetylene. Rendiconti Lincei 2017, 28, 51-58. [CrossRef]

24. Oberhauser, W.; Evangelisti, C.; Jumde, R.; Petrucci, G.; Bartoli, M.; Frediani, M.; Mannini, M.; Capozzoli, L.; Passaglia, E.; Rosi, L. Palladium-nanoparticles on end-functionalized poly (lactic acid)-based stereocomplexes for the chemoselective cinnamaldehyde hydrogenation: Effect of the end-group. J. Catal. 2015, 330, 187-196. [CrossRef]

25. Petrucci, G.; Oberhauser, W.; Bartoli, M.; Giachi, G.; Frediani, M.; Passaglia, E.; Capozzoli, L.; Rosi, L. Pd-nanoparticles supported onto functionalized poly (lactic acid)-based stereocomplexes for partial alkyne hydrogenation. Appl. Catal. A Gen. 2014, 469, 132-138. [CrossRef]

26. Giachi, G.; Frediani, M.; Oberhauser, W.; Passaglia, E. Pd (II)-pyridine macrocomplexes based on poly (lactide). J. Polym. Sci. Part A Polym. Chem. 2011, 49, 4708-4713. [CrossRef]

27. Rillema, D.P.; Stoyanov, S.R.; Cruz, A.J.; Nguyen, H.; Moore, C.; Huang, W.; Siam, K.; Jehan, A.; KomReddy, V. HOMO-LUMO energy gap control in platinum (ii) biphenyl complexes containing 2, 2'-bipyridine ligands. Dalton Trans. 2015, 44, 17075-17090. [CrossRef] [PubMed] 
28. Pazderski, L.; Szłyk, E.; Sitkowski, J.; Kamieński, B.; Kozerski, L.; Toušek, J.; Marek, R. Experimental and quantum-chemical studies of $15 \mathrm{~N}$ NMR coordination shifts in palladium and platinum chloride complexes with pyridine, 2, 2'-bipyridine and 1, 10-phenanthroline. Magn. Reson. Chem. 2006, 44, 163-170. [CrossRef] [PubMed]

29. Frediani, M.; Oberhauser, W.; Passaglia, E.; Rosi, L.; Bandelli, D.; Bartoli, M.; Petrucci, G. Pyridine and Bipyridine End-Functionalized Polylactide: Synthesis and Catalytic Applications. In Handbook of Composites from Renewable Materials, Functionalization; John Wiley \& Sons: Hoboken, NJ, USA, 2017; Volume 4, p. 47.

30. Kawanishi, Y.; Funaki, T.; Yatabe, T.; Suzuki, Y.; Miyamoto, S.; Shimoi, Y.; Abe, S. Spectral Evidence and DFT Calculations on the Formation of Bis (2, 2'-bipyridine) platinum (II)-N-Base Adducts. Inorg. Chem. 2008, 47, 3477-3479. [CrossRef] [PubMed]

31. Oberhauser, W.; Evangelisti, C.; Jumde, R.P.; Psaro, R.; Vizza, F.; Bevilacqua, M.; Filippi, J.; Machado, B.F.; Serp, P. Platinum on carbonaceous supports for glycerol hydrogenolysis: Support effect. J. Catal. 2015, 325, 111-117. [CrossRef]

32. Ji, X.; Niu, X.; Li, B.; Han, Q.; Yuan, F.; Zaera, F.; Zhu, Y.; Fu, H. Selective hydrogenation of cinnamaldehyde to cinnamal alcohol over platinum/graphene catalysts. ChemCatChem 2014, 6, 3246-3253. [CrossRef]

33. Malathi, R.; Viswanath, R.P. Citral hydrogenation on supported platinum catalysts. Appl. Catal. A Gen. 2001, 208, 323-327. [CrossRef]

(C) 2019 by the authors. Licensee MDPI, Basel, Switzerland. This article is an open access article distributed under the terms and conditions of the Creative Commons Attribution (CC BY) license (http://creativecommons.org/licenses/by/4.0/). 